University of Nebraska - Lincoln

DigitalCommons@University of Nebraska - Lincoln

2010

\title{
Mortality Patterns of Army Chemical Corps Veterans Who were Occupationally Exposed to Herbicides in Vietnam
}

Yasmin Cypel

Department of Veterans Affairs, yasmin.cypel@va.gov

Han Kang

Department of Veterans Affairs

Follow this and additional works at: https://digitalcommons.unl.edu/publichealthresources

Part of the Public Health Commons

Cypel, Yasmin and Kang, Han, "Mortality Patterns of Army Chemical Corps Veterans Who were Occupationally Exposed to Herbicides in Vietnam" (2010). Public Health Resources. 168.

https://digitalcommons.unl.edu/publichealthresources/168

This Article is brought to you for free and open access by the Public Health Resources at DigitalCommons@University of Nebraska - Lincoln. It has been accepted for inclusion in Public Health Resources by an authorized administrator of DigitalCommons@University of Nebraska - Lincoln. 


\title{
Mortality Patterns of Army Chemical Corps Veterans Who were Occupationally Exposed to Herbicides in Vietnam
}

\author{
YASMIN CYPEL, PhD, AND HAN KANG, DrPH
}

\begin{abstract}
PURPOSE: This research examined the risk of disease-related mortality of the Army Chemical Corps (ACC) veterans who handled/sprayed herbicides in Vietnam in comparison with their non-Vietnam veteran peers or U.S. men.

METHODS: Vital status was determined through December 31, 2005. All-cause mortality and cause-specific mortality were compared for individuals who served in Vietnam $(n=2872)$ versus those who did not $(n=2737)$. Similar analyses were completed on a subset of the original Vietnam cohort that consisted of individuals who either reported spraying herbicide $(n=662)$ or not $(n=811)$. The observed deaths for each of the two base cohorts were also compared with expected deaths for U.S. men. RESULTS: Statistically significant excess mortality was found for ACC Vietnam veterans for chronic obstructive pulmonary disease (adjusted relative risk [ARR], 4.82; 95\% confidence interval [95\% CI], 1.10-21.18). When examining patterns for veterans in the Vietnam veteran subset, we found nonsignificant elevated ARRs among herbicide sprayers for all-cause, respiratory system disease, and respiratory system cancer mortality. Compared with U.S. men, the Vietnam veteran cohort had significant excess mortality for all-causes (standardized mortality ratio [SMR], 1.13; 95\% CI, 1.04-1.23), respiratory system cancer (SMR, 1.35; 95\% CI, 1.03-1.73), nonmalignant respiratory system disease (SMR, 1.58; 95\% CI, 1.08-2.23), and miscellaneous malignant cancers (SMR, 1.77; 95\% CI, 1.03-2.84).

CONCLUSIONS: The risk of mortality from respiratory disease (malignant or nonmalignant) was significantly greater for ACC Vietnam veterans in comparison with their non-Vietnam veteran peers and U.S. men. Herbicide exposure could be contributing to the patterns observed. Because of the unique nature of their military duties and study limitations, findings may not be generalizeable to Vietnam veterans as a whole. Ann Epidemiol 2010;20:339-346. Published by Elsevier Inc.
\end{abstract}

KEY wORDS: Army Chemical Corps, Herbicides, Mortality, Veterans, Vietnam War.

\section{INTRODUCTION}

The members of the Army Chemical Corps (ACC) were responsible for handling and spraying herbicides around the perimeters of military base camps in Vietnam. They may constitute the largest cohort of Vietnam-era veterans (those who served in Vietnam and those who served in areas outside Vietnam during the War) who were directly exposed to Agent Orange and its contaminant 2,3,7,8-tetrachlorodibenzo-p-dioxin (TCDD). The extent of herbicide exposure of this cohort of veterans was thought to be similar to those of the US Air Force Ranch Hand personnel who were involved with the fixed wing aircraft spraying of herbicides

From the Environmental Epidemiology Service (135), Department of Veterans Affairs (Y.C., H.K.); and George Washington University School of Public Health and Health Services (H.K.), Washington, DC.

Address correspondence to: Yasmin Cypel, PhD, Environmental Epidemiology Service (135), Department of Veterans Affairs, 810 Vermont Avenue, NW, Washington, DC 20420. Tel.: 202-266-4552; Fax: 202495-5973. E-mail: yasmin.cypel@va.gov.

Supported by the War Related Illness and Injury Study Center, Veterans Affairs Medical Center, 50 Irving Street, NW, Washington, DC 20422.

Received May 1, 2009; accepted February 10, 2010. during the Vietnam War. The members of the ACC Vietnam veterans who reported spraying herbicides as part of their military duties in Vietnam have been demonstrated to have significantly increased serum TCDD concentrations and a significantly increased risk for diabetes, heart disease, hypertension, and nonmalignant respiratory disease associated with the exposure (1). None of these conditions was significantly associated with Vietnam service while adjusting for herbicide spraying and other covariates. The Institute of Medicine committee that reviewed scientific literature related to the health effects of Agent Orange and its contaminant stated that the ACC veterans represent our best opportunity to understand the health effects of exposure to TCDD and herbicides used in Vietnam and recommended further follow-up of these veterans $(2,3)$.

The mortality experience of these cohorts of ACC Vietnam-era veterans was last reported in 1997 (4). In comparison with their non-Vietnam veteran peers, the ACC Vietnam veterans demonstrated a significantly greater risk of deaths from digestive system diseases. Nonsignificant elevated relative risks also were observed for all cancers combined, digestive and respiratory systems cancers, and nonmalignant respiratory system diseases. For the Vietnam 
Selected Abbreviations and Acronyms

ACC $=$ Army Chemical Corps

TCDD $=$ 2,3,7,8-tetrachlorodibenzo-p-dioxin

BIRLS $=$ Beneficiary Identification and Records Locator Subsystem

SSA $=$ Social Security Administration

NDI $=$ National Death Index

$\mathrm{ICD}=$ International Classification of Diseases

$\mathrm{NCI}=$ National Cancer Institute

NIOSH $=$ National Institute for Occupational Safety and Health

SEER = Surveillance, Epidemiology, and End Results

$\mathrm{BMI}=$ body mass index

$95 \% \mathrm{CI}=95 \%$ confidence interval

$\mathrm{SMR}=$ standardized mortality ratio

$\mathrm{ARR}=$ adjusted relative risk

$\mathrm{COPD}=$ chronic obstructive pulmonary disease

veterans, patterns of elevated but nonsignificant mortality risk persisted for disease of the digestive and respiratory systems and for selected cancer sites when compared to the mortality rates for U.S. men. The current study has added 14 years to the observation period since the last vital status follow-up in 1991 (4), extending the total follow-up period to almost 35 years. The purpose of the study was to determine the long-term mortality experience of ACC veterans who were occupationally exposed to the herbicide Agent Orange in Vietnam.

\section{METHODS}

\section{Study Subjects}

Figure 1 shows the major steps in the identification and selection of the ACC Vietnam-era veterans. The selection of study subjects was described in detail elsewhere (4). The final Vietnam cohort included 2872 veterans who served in Vietnam during the period of combat involvement in Vietnam (July 1, 1965-March 28, 1973) and whose military occupation was in chemical operations. Non-Vietnam veterans, who comprised 2737 men who served in the same military occupation during the same period as the Vietnam veterans but never in Southeast Asia, were selected as a comparison cohort. Males in the U.S. population were also included as a comparison group to determine whether outcomes were generally more related to being in the military rather than service in Vietnam. Moreover, a subgroup of 1473 ACC Vietnam veterans who participated in the 1999 to 2000 ACC Vietnam Veteran Health Study (1) was identified by their responses to a question related to herbicide spraying while in the military. A total of 662 veterans reported a history of handling/spraying herbicides, and 811 veterans did not. These Vietnam veterans were used in a separate comparison examining mortality among those who reported spraying herbicide versus those who did not.

\section{Determination of Vital Status and Collection of Cause of Death Data}

The ACC veterans who were alive as of the last vital status update in 1991 (4) were matched against data from the VA Beneficiary Identification and Records Locator Subsystem (BIRLS) Death File and Social Security Administration (SSA) Death Master File to identify persons who died between January 1, 1992, and December 31, 2005. Data on those who died since the last follow-up in 1991 were

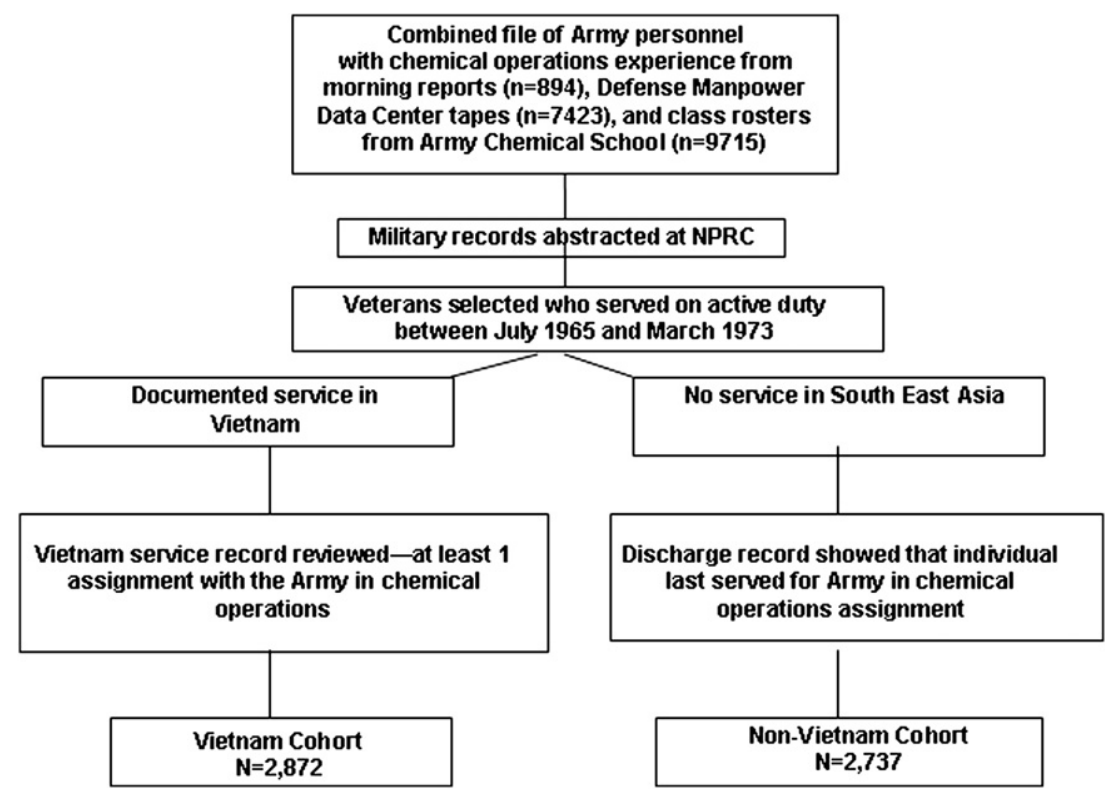

FIGURE 1. Identification and selection of the two Army Chemical Corps cohorts (4). 
submitted to the National Center for Health Statistics in 2007 for conduct of a National Death Index (NDI)-Plus search from which underlying cause of death was obtained. Codes were based on the International Classification of Diseases (ICD) version 9 (5). Death certificates were not obtained from states for verification. Mortality categories were developed on the basis of previous studies $(1,4,6)$, the frequency distributions of the resultant ICD 9 codes, and the National Cancer Institute's (NCI) Surveillance, Epidemiology, and End Results (SEER) analytical tools (Surveillance Research Program, National Cancer Institute SEER*Stat software, Version 6.4.4. Available at: www.seer. cancer.gov/seerstat). The major mortality groupings used in this analysis are malignant neoplasms and nonmalignant disease-related causes of death (excludes external causes but includes, for example, major diseases other than malignant cancers such as circulatory system disease, digestive system disease, and respiratory system disease).

\section{Statistical Analysis}

The variable, "days of follow-up" ("time to event" or "survival time"), was computed to obtain person-years at risk of dying. They were counted for each person from the earlier of either the date when an individual left military service or the date the last U.S. troops left Vietnam (March $28,1973)$ and to either the date of death or end of follow-up (December 31, 2005). Crude mortality rates and ratios were computed for all causes and for each of the cause-specific mortality categories. By the use of a competing risk approach (7), the effect of the covariates on survival time for each of the events (e.g., each of the cause of death categories such as respiratory system cancer, circulatory system disease, etc.) was estimated while deaths from other events were censored. "Time to event" was regressed onto race, age at entry into follow-up, rank, total months of military service, and Vietnam-service status (whether or not an individual served in Vietnam). The relationship between "time to event" was examined relative to Vietnam-service status while controlling for all other covariates, for all causes of death and then for each cause-specific mortality category. Proportionality of the Cox proportional hazard model was tested and there was no evidence to suggest that this assumption was violated.

Similar analyses were conducted on a subgroup $(n=1473)$ of the Vietnam cohort to examine associations between self-reported herbicide spraying status and mortality from various causes while controlling for Vietnam-service status (by including only those who served in Vietnam) and other covariates (through regression). The additional covariates used in the Vietnam subgroup analysis included herbicide spraying activity, body mass index (BMI), and smoking status that were obtained from information collected in the earlier ACC Vietnam Veteran Health Study (1). Not all the categories presented for comparison of the Vietnam and non-Vietnam cohorts are presented in the tabulated results for the Vietnam subgroup analysis because of small numbers, but we still deemed it important to represent a range of categories to demonstrate possible patterns.

Relative risks were adjusted for potential confounders and 95\% confidence intervals (95\% CI) obtained using SAS system ® software (Version 9.1; SAS Institute Inc. SAS/STAT Software, Cary, NC: SAS Institute). Bonferroni-like adjustments were not performed for the multiple tests completed because these types of adjustments increase the probability of concluding that no difference exists when one actually does $(8,9)$ and because the determination of how many tests to use in modifying the $P$ value is arbitrary (9). Cause-specific standardized mortality ratios (SMRs) and 95\% CIs were obtained by the use of the NCI SEER*Prep and SEER*Stat software (Surveillance Research Program, National Cancer Institute SEER*Stat software), which adjusts for sex, race, age, and calendar period of death and bases expected mortality rates on those obtained for U.S. population males. This research was approved by the Institutional Review Board and the Research and Development Committee of the Veterans Affairs Medical Center, Washington, DC, in the Fall 2007.

\section{RESULTS}

As presented in Table 1, there were a total of 948 deaths representing approximately $17 \%$ of the individuals in the Vietnam and non-Vietnam cohorts; 624 deaths occurred since the 1991 update (4). The mean length of follow-up for the two cohorts on average was approximately 32 years, with total person-years at risk estimated to be 93,318 and 89,850 for the Vietnam cohort and non-Vietnam cohort, respectively (not shown in tables). Individuals in each of the cohorts were predominantly white and enlisted, and the median age was estimated to be about 24 years at

TABLE 1. Vital status determination for Army Chemical Corps veterans ( $\mathrm{n}=5609$ ) of the Vietnam War by Vietnamservice status through December 31, 2005

\begin{tabular}{|c|c|c|c|c|c|c|}
\hline \multirow[b]{3}{*}{ Vital status } & \multicolumn{4}{|c|}{ Vietnam-service status $^{\mathrm{a}}$} & & \\
\hline & \multicolumn{2}{|c|}{$\begin{array}{l}\text { Vietnam cohort } \\
\quad(\mathrm{n}=2872)\end{array}$} & \multicolumn{2}{|c|}{$\begin{array}{l}\text { Non-Vietnam cohort } \\
\quad(\mathrm{n}=2737)\end{array}$} & \multicolumn{2}{|c|}{ All } \\
\hline & Number & $\%$ & Number & $\%$ & Number & $\%$ \\
\hline Alive & 2279 & 79.4 & 2382 & 87.0 & 4661 & 83.1 \\
\hline Deceased $^{\mathrm{b}}$ & 593 & 20.6 & 355 & 13.0 & 948 & 16.9 \\
\hline Total & 2872 & 100.0 & 2737 & 100.0 & 5609 & 100.0 \\
\hline
\end{tabular}

"Men who either served in Vietnam ("Vietnam" cohort) or who never served in Southeast Asia ("non-Vietnam" cohort) during the Vietnam War.

bercentages of Vietnam and non-Vietnam cohorts, respectively, who are deceased are significantly different $(p<0.0001)$ by the Wilcoxon rank sum test. 
the start of follow-up and 58 at the end of follow-up (Table 2). Almost $90 \%$ of veterans in each of the study groups were between the ages of 50 and 70 at the end of follow-up (not shown in tables).

The adjusted relative risks (ARR; Table 3 ) between the ACC Vietnam veterans and non-Vietnam veterans were generally greater for all causes of death (ARR, 1.13; 95\% CI, 0.98-1.30), all cancer combined (1.15; 0.85-1.55), and major categories of diseases such as the diseases of the circulatory system $(1.21 ; 0.93-1.58)$, respiratory system $(2.20 ; 0.99-4.91)$, and digestive system $(1.80 ; 0.80-4.03)$. The risk of death attributable to chronic obstructive pulmonary disease was significantly greater $(4.82 ; 1.10-21.18)$ among ACC Vietnam veterans relative to their nonVietnam veteran peers.

Similar patterns of excess mortality among the ACC Vietnam veterans persisted when comparisons were made with the U.S. male population (Table 4). The SMRs were significantly greater for all causes of death (SMR, 1.13; 95\% CI, $1.04-1.23)$, respiratory cancers $(1.35 ; 1.03-1.73)$, and nonmalignant respiratory system disease $(1.58 ; 1.08-2.23)$. Nonsignificant elevations were found for all cancer combined $(1.13 ; 0.95-1.33)$ and circulatory system disease (1.16;

TABLE 2. Characteristics of Army Chemical Corps veterans $(\mathrm{n}=5609)$ of the Vietnam War by Vietnam-service status

\begin{tabular}{|c|c|c|c|c|c|c|}
\hline \multirow[b]{3}{*}{ Characteristic $^{\mathrm{b}}$} & \multicolumn{6}{|c|}{ Vietnam-service status $^{\mathrm{a}}$} \\
\hline & \multicolumn{3}{|c|}{$\begin{array}{l}\text { Vietnam cohort } \\
\quad(\mathrm{n}=2872)\end{array}$} & \multicolumn{3}{|c|}{$\begin{array}{l}\text { Non-Vietnam cohort } \\
\quad(\mathrm{n}=2737)\end{array}$} \\
\hline & Number & $\%$ & Median & Number & $\%$ & Median \\
\hline \multicolumn{7}{|l|}{$\begin{array}{l}\text { Age (years) at entry } \\
\text { to follow-up }\end{array}$} \\
\hline$<20$ & 18 & 0.6 & & 136 & 5.0 & \\
\hline $20-24$ & 1605 & 55.9 & & 1856 & 67.8 & \\
\hline $25-29$ & 588 & 20.5 & & 608 & 22.2 & \\
\hline$>29$ & 661 & 23.0 & & 137 & 5.0 & \\
\hline \multicolumn{7}{|l|}{ Age at: } \\
\hline Entry to follow-up ${ }^{c}$ & & & 24.0 & & & 23.0 \\
\hline End of follow-up & & & 58.8 & & & 57.1 \\
\hline \multicolumn{7}{|l|}{ Race } \\
\hline White & 2207 & 76.9 & & 2230 & 81.5 & \\
\hline Nonwhite & 665 & 23.2 & & 507 & 18.5 & \\
\hline \multicolumn{7}{|l|}{ Rank } \\
\hline Enlisted & 2716 & 94.6 & & 2469 & 90.2 & \\
\hline Officer & 156 & 5.4 & & 268 & 9.8 & \\
\hline \multicolumn{7}{|l|}{ Duration of active duty } \\
\hline$<24$ months & 654 & 22.8 & & 745 & 27.2 & \\
\hline $24-36$ months & 1172 & 40.8 & & 1632 & 59.6 & \\
\hline$>36$ months & 1046 & 36.4 & & 360 & 13.2 & \\
\hline
\end{tabular}

aMen who either served in Vietnam ("Vietnam" cohort) or who never served in Southeast Asia ("non-Vietnam" cohort) during the Vietnam War.

bistributions of these characteristics were significantly different $(p<0.0001)$ by the Wilcoxon rank sum test.

'Start of follow-up was designated as either the end of the Vietnam War (March 28, 1973) or service release date, whichever occurred first. The end of follow-up was either December 31, 2005, or date of death.
1.00-1.34). In contrast, in most categories, cause-specific SMRs for non-Vietnam veterans were lower than 1.0.

Among a subgroup of Vietnam veterans, ARRs were generally elevated for veterans who sprayed herbicides compared with veterans who did not spray herbicides, but none were statistically significant (Table 5). The ARRs for all causes, respiratory system cancers, and nonmalignant respiratory system diseases were 1.46 (95\% CI, 1.00-2.12), 1.35 (95\% CI, 0.53-3.43), and 2.24 (95\% CI, 0.42-11.83), respectively, when we adjusted for all other covariates, including smoking status.

\section{DISCUSSION}

The ACC veterans who served in Vietnam had the potential for a high level of Agent Orange exposure because of their specific duties involving the storage, preparation, and application of herbicides. Although not statistically significant, ACC Vietnam veterans experienced an excess in mortality from all causes, all cancer combined, and circulatory, respiratory, and digestive system diseases relative to their non-Vietnam veteran peers. These observations were also replicated when the mortality experience of these Vietnam veterans was compared with U.S. men. Because of the inherent advantage associated with a statistical method based on comparisons to expected numbers derived from U.S. national mortality statistics, the SMRs for all causes, respiratory cancers, and nonmalignant respiratory system disease were statistically significant, whereas the SMR for circulatory system disease was elevated but not significant. Moreover, a comparison only among Vietnam veterans demonstrated that veterans who had a greater potential for herbicide exposure exhibited a greater risk of death from many of the same categories of diseases than other Vietnam veterans who had not handled/sprayed herbicides like Agent Orange.

These observations from this mortality study are consistent with the results from a health survey conducted among the same cohorts of ACC Vietnam-era veterans in 1999/ 2000 (1). Among ACC veterans who participated in a health survey $(n=2927)$, there was a statistically significant association between a history of spraying herbicide in Vietnam and physician-diagnosed diabetes, heart disease, hypertension, and chronic respiratory diseases while controlling for Vietnam-service status, race, BMI, military rank, cigarette smoking, and age at time of interview. Thus, these findings were independent from the effect of military service in Vietnam in general.

Our positive finding of elevated relative risk (ARR, 1.29; 95\% CI, 0.79-2.10) and elevated SMR (1.35; 1.03-1.73) for respiratory cancer among ACC Vietnam veterans is consistent with the studies of industrial production workers who were occupationally exposed to dioxin (10-13) as well 
TABLE 3. Mortality among Army Chemical Corps veterans of the Vietnam War by Vietnam-service status through December 31,2005

\begin{tabular}{|c|c|c|c|c|c|c|c|c|}
\hline \multirow[b]{3}{*}{ Underlying cause of mortality } & \multirow[b]{3}{*}{$\begin{array}{c}\text { Total } \\
\text { observed }\end{array}$} & \multicolumn{4}{|c|}{ Vietnam-service status $^{\mathrm{a}}$} & \multirow[b]{3}{*}{$\begin{array}{c}\text { Crude } \\
\text { rate ratio }\end{array}$} & \multirow[b]{3}{*}{$\begin{array}{c}\text { Adjusted } \\
\text { relative risk }\end{array}$} & \multirow[b]{3}{*}{$95 \% \mathrm{CI}$} \\
\hline & & \multicolumn{2}{|c|}{$\begin{array}{l}\text { Vietnam cohort } \\
\quad(\mathrm{n}=2872)\end{array}$} & \multicolumn{2}{|c|}{$\begin{array}{c}\text { Non-Vietnam } \\
\text { cohort }(\mathrm{n}=2737)\end{array}$} & & & \\
\hline & & Observed & $\begin{array}{l}\text { Crude } \\
\text { rate } / 10^{4} \mathrm{~b}\end{array}$ & Observed & $\begin{array}{c}\text { Crude } \\
\text { rate } / 10^{4}\end{array}$ & & & \\
\hline All causes ${ }^{\mathrm{e}}$ & 948 & 593 & 63.55 & 355 & 39.51 & 1.61 & 1.13 & $0.98-1.30$ \\
\hline Malignant cancers & 216 & 142 & 15.22 & 74 & 8.24 & 1.85 & 1.15 & $0.85-1.55$ \\
\hline Oral cavity and pharynx & 8 & 6 & 0.64 & 2 & 0.22 & 2.89 & 1.68 & $0.33-8.73$ \\
\hline Digestive system & 52 & 33 & 3.54 & 19 & 2.11 & 1.67 & 1.01 & $0.56-1.83$ \\
\hline Respiratory system & 86 & 60 & 6.43 & 26 & 2.89 & 2.22 & 1.29 & $0.79-2.10$ \\
\hline Prostate & 7 & 5 & 0.54 & 2 & 0.22 & 2.41 & 1.02 & $0.19-5.64$ \\
\hline Testicular & 2 & 2 & 0.21 & 0 & - & - & - & - \\
\hline Skin & 9 & 5 & 0.54 & 4 & 0.45 & 1.20 & 1.52 & $0.37-6.20$ \\
\hline Brain & 6 & 4 & 0.43 & 2 & 0.22 & 1.93 & 1.67 & $0.27-10.19$ \\
\hline Lymphopoietic & 12 & 6 & 0.64 & 6 & 0.67 & 0.96 & 1.10 & $0.35-3.48$ \\
\hline Leukemia & 6 & 2 & 0.21 & 4 & 0.45 & 0.54 & 0.56 & $0.10-3.20$ \\
\hline $\begin{array}{l}\text { Miscellaneous malignant } \\
\text { cancers }^{f}\end{array}$ & 28 & 17 & 1.82 & 11 & 1.22 & 1.49 & 0.86 & $0.39-1.92$ \\
\hline \multicolumn{9}{|l|}{$\begin{array}{l}\text { Other major diseases } \\
\text { (noncancers) }\end{array}$} \\
\hline Diabetes mellitus & 27 & 20 & 2.14 & 7 & 0.78 & 2.75 & 1.79 & $0.73-4.39$ \\
\hline Circulatory system disease & 272 & 184 & 19.72 & 88 & 9.79 & 2.01 & 1.21 & $0.93-1.58$ \\
\hline Hypertension & 8 & 5 & 0.54 & 3 & 0.33 & 1.60 & 0.85 & $0.19-3.86$ \\
\hline Cerebrovascular disease & 36 & 27 & 2.89 & 9 & 1.00 & 2.89 & 1.48 & $0.67-3.27$ \\
\hline Respiratory system disease & 40 & 32 & 3.43 & 8 & 0.89 & 3.85 & 2.20 & $0.99-4.91^{\mathrm{g}}$ \\
\hline Pneumonia and influenza & 18 & 12 & 1.29 & 6 & 0.67 & 1.93 & 1.30 & $0.46-3.62$ \\
\hline $\begin{array}{l}\text { Chronic obstructive } \\
\text { pulmonary disease }\end{array}$ & 22 & 20 & 2.14 & 2 & 0.22 & 9.63 & 4.82 & $1.10-21.18^{\mathrm{h}}$ \\
\hline Digestive system disease & 30 & 21 & 2.25 & 9 & 1.00 & 2.25 & 1.80 & $0.80-4.03$ \\
\hline Cirrhosis of liver & 28 & 19 & 2.04 & 9 & 1.00 & 2.03 & 1.74 & $0.77-3.94$ \\
\hline
\end{tabular}

$95 \% \mathrm{CI}=95 \%$ confidence interval.

"Men who either served in Vietnam ("Vietnam" cohort) or who never served in Southeast Asia ("non-Vietnam" cohort) during the Vietnam War.

${ }^{\mathrm{b}}$ Crude mortality rate $=$ no. deaths per $10^{4}$ person-years at risk.

${ }^{\mathrm{c}}$ Ratio of crude mortality rate of Vietnam to non-Vietnam cohorts (crude rate ratio). Rounding may have an impact on estimates.

${ }^{\mathrm{d}}$ Estimate derived from Cox proportional hazards survival analysis modeling adjusting for race, rank, duration of military service, and age at entry into follow-up. Estimates based on low total observations should be interpreted with caution.

eMainly mortality from malignant cancers, other major non-cancer diseases, and external causes.

${ }^{\mathrm{f}}$ Mainly malignant neoplasms without specification of site.

${ }^{\mathrm{g}}$ Marginally significant $(p=.0546)$.

h95\% CI does not include 1 .

as studies of Australian Vietnam veterans (14-16) and U.S. Air Force veterans $(17,18)$. Research on Air Force veterans who survived at least 20 years after their service in Vietnam showed a nonsignificant increase in mortality for bronchus and lung cancers relative to a comparison cohort of more than 19,000 veterans who served in Vietnam but did not spray herbicide (17). Also, cancer incidence between 1982 and 2003 among 1482 Air Force veterans who served in Southeast Asia indicated that the cancer risk was greatest in those with the greatest TCDD levels (18). However, it should be noted that many Vietnam veteran studies and environmental studies without objective assessment of exposure did not find an association between exposure and the mortality risk attributable to respiratory cancer $(2,3)$. Therefore, the evidence for an association between exposure to Agent Orange or dioxin and the risk of death due to respiratory cancer is considered limited but suggestive by the Institute of Medicine committee (3).

In contrast to the finding of elevated respiratory cancer among ACC Vietnam veterans, a few previous studies reported elevated mortality risk attributable to nonmalignant respiratory diseases, especially chronic obstructive pulmonary disease (COPD) among individuals who were potentially exposed to dioxin. In the 15-year period after the Seveso accident, increased deaths from COPD were observed among male residents of the area where dioxin contamination was the greatest (relative risk, 3.7; 95\% CI, 1.4-9.9) (19). In a health study of Australian Vietnam veterans, a four-fold excess prevalence of COPD was found in Vietnam veterans (20).

Again, there are many studies that did not support our observation of elevated mortality attributable to nonmalignant respiratory disorder. Notably, the National Institute for 
TABLE 4. Comparison of mortality among Army Chemical Corps veterans of the Vietnam War by Vietnam-service status to males in the U.S. population

\begin{tabular}{|c|c|c|c|c|c|c|c|}
\hline \multirow[b]{3}{*}{ Underlying cause of mortality } & \multirow[b]{3}{*}{ Total observed } & \multicolumn{6}{|c|}{ Vietnam-service status ${ }^{\mathrm{a}}$} \\
\hline & & \multicolumn{3}{|c|}{ Vietnam cohort $(\mathrm{n}=2872)$} & \multicolumn{3}{|c|}{$\begin{array}{l}\text { Non-Vietnam cohort } \\
\quad(\mathrm{n}=2737)\end{array}$} \\
\hline & & Observed & $\mathrm{SMR}^{\mathrm{b}}$ & $95 \% \mathrm{CI}$ & Observed & SMR & $95 \% \mathrm{CI}$ \\
\hline All causes ${ }^{\mathrm{c}}$ & 948 & 593 & 1.13 & $1.04-1.23^{\mathrm{d}}$ & 355 & 0.92 & $0.83-1.02$ \\
\hline Malignant cancers & 216 & 142 & 1.13 & $0.95-1.33$ & 74 & 0.92 & $0.72-1.16$ \\
\hline Oral cavity and pharynx & 8 & 6 & 1.51 & $0.55-3.29$ & 2 & 0.78 & $0.09-2.83$ \\
\hline Digestive system & 52 & 33 & 1.01 & $0.69-1.41$ & 19 & 0.90 & $0.54-1.40$ \\
\hline Respiratory system & 86 & 60 & 1.35 & $1.03-1.73^{\mathrm{d}}$ & 26 & 1.01 & $0.66-1.48$ \\
\hline Prostate & 7 & 5 & 1.05 & $0.34-2.45$ & 2 & 0.95 & $0.12-3.43$ \\
\hline Testicular & 2 & 2 & 3.63 & $0.44-13.10$ & 0 & - & - \\
\hline Skin & 9 & 5 & 1.33 & $0.43-3.10$ & 4 & 1.31 & $0.36-3.36$ \\
\hline Brain & 6 & 4 & 0.87 & $0.24-2.22$ & 2 & 0.54 & $0.07-1.97$ \\
\hline All lymphopoietic & 12 & 6 & 0.46 & $0.17-0.99^{d}$ & 6 & 0.63 & $0.23-1.38$ \\
\hline Leukemia & 6 & 2 & 0.42 & $0.05-1.51$ & 4 & 1.15 & $0.31-2.95$ \\
\hline Miscellaneous malignant cancers ${ }^{\mathrm{e}}$ & 28 & 17 & 1.77 & $1.03-2.84^{\mathrm{d}}$ & 11 & 1.78 & $0.89-3.18$ \\
\hline \multicolumn{8}{|l|}{ Other major diseases } \\
\hline Diabetes mellitus & 27 & 20 & 1.50 & $0.92-2.32$ & 7 & 0.78 & $0.31-1.61$ \\
\hline Circulatory system disease & 272 & 184 & 1.16 & $1.00-1.34$ & 88 & 0.87 & $0.69-1.07$ \\
\hline Hypertension & 8 & 5 & 2.08 & $0.67-4.84$ & 3 & 1.98 & $0.41-5.78$ \\
\hline Cerebrovascular disease & 36 & 27 & 1.47 & $0.97-2.13$ & 9 & 0.78 & $0.36-1.48$ \\
\hline Respiratory system disease & 40 & 32 & 1.58 & $1.08-2.23^{\mathrm{d}}$ & 8 & 0.66 & $0.28-1.30$ \\
\hline Pneumonia and influenza & 18 & 12 & 1.51 & $0.78-2.63$ & 6 & 1.11 & $0.41-2.42$ \\
\hline Chronic obstructive pulmonary disease & 22 & 20 & 1.62 & $0.99-2.51$ & 2 & 0.30 & $0.04-1.07$ \\
\hline Digestive system disease & 30 & 21 & 1.05 & $0.65-1.61$ & 9 & 0.59 & $0.27-1.11$ \\
\hline Cirrhosis of liver & 28 & 19 & 1.01 & $0.61-1.57$ & 9 & 0.62 & $0.28-1.17$ \\
\hline
\end{tabular}

SMR = standardized mortality ratio; $95 \% \mathrm{CI}=95 \%$ confidence interval.

aMen who either served in Vietnam ("Vietnam" cohort) or who never served in Southeast Asia ("non-Vietnam" cohort) during the Vietnam War.

bSR as computed by the use of the NCI's SEER*Stat (Version 6.4.4, April 24, 2008) and SEER*Prep (Version 2.4.0, May 2007) software. Statistics represent observed to expected number of deaths based on rates for men in the U.S. population.

${ }^{\mathrm{C}}$ Mainly mortality from malignant cancers, other major non-cancer diseases, and external causes.

$\mathrm{d}_{95} \mathrm{CI}$ does not include 1.

eMainly malignant neoplasms without specification of site.

Occupational Safety and Health (NIOSH) study of workers exposed to chemicals contaminated with dioxin did not find elevated prevalence of chronic bronchitis, COPD, abnormal pulmonary function parameters, or cardiovascular diseases including hypertension (21). A mortality study of the same NIOSH cohort, however, reported an increased overall cancer mortality and ischemic heart disease. Although statistically significant trends for cancer (15-year lag time) and heart disease (no lag time) with increasing exposure also were reported, diabetes showed a negative exposure-response trend (22).

In the current study, respiratory cancer and nonmalignant respiratory disease mortality were significantly greater in the Vietnam cohort compared with U.S. men whereas the SMRs for these diseases were at approximately 1.0 or below for the non-Vietnam cohort, implicating service in Vietnam, or some aspect of this such as herbicide spray activity, as a possible factor in these events. The excess mortality occurring within the same organ system for different disease entities (e.g., cancers and noncancers) adds greater relevance to the issue of respiratory health in ACC Vietnam veterans particularly if inhalation is considered a main route of herbicide exposure.

We found a statistically significant deficit for the SMR for lymphopoietic cancers. The direction and magnitude of the SMRs were within range of one another for each of the cohorts in comparison to U.S. males. This and the ARR of 1.10 between Vietnam and non-Vietnam veterans for this group of cancers indicates that lower mortality from this cause is not necessarily specific to Vietnam-service status but possibly to military service more generally. Service in Vietnam during the Vietnam War did not increase the risk of non-Hodgkin's lymphoma $(23,24)$ or Hodgkin's disease $(25,26)$ when examined in several case-control studies of male veterans.

Certain study limitations should be considered when evaluating these results. A potential limitation of this study is the reliance on death certificates for information on cause of death. Their accuracy in recording causes of death may be variable (27-29), especially where cancer-related deaths are concerned (28). Disease diagnosis at time of death and ICD classification are potentially susceptible to measurement errors that may impact the quality of cause of death statistics 
TABLE 5. Association between mortality and self-reported herbicide spraying status among Army Chemical Corps veterans who served in Vietnam ${ }^{a}$

\begin{tabular}{|c|c|c|c|}
\hline Underlying cause of mortality & $\begin{array}{l}\text { Total number } \\
\text { of deaths }\end{array}$ & $\mathrm{ARR}^{\mathrm{a}}$ & $95 \%$ CI \\
\hline All causes ${ }^{\mathrm{b}}$ & 120 & 1.46 & $1.00-2.12^{\mathrm{c}}$ \\
\hline Cancer & 41 & 1.00 & $0.53-1.90$ \\
\hline Digestive system cancer & 14 & 0.65 & $0.21-2.00$ \\
\hline Respiratory system cancer & 19 & 1.35 & $0.53-3.43$ \\
\hline Miscellaneous malignant cancer $^{\mathrm{d}}$ & 3 & 3.63 & $0.32-41.30$ \\
\hline Respiratory system disease & 8 & 2.24 & $0.42-11.83$ \\
\hline Pulmonary disease & 6 & 3.55 & $0.39-32.14$ \\
\hline Diabetes & 11 & 2.21 & $0.61-8.02$ \\
\hline Circulatory system disease & 37 & 1.17 & $0.60-2.28$ \\
\hline Hypertension & 3 & 2.35 & $0.19-28.52$ \\
\hline Cerebrovascular disease & 6 & 2.12 & $0.37-12.30$ \\
\hline
\end{tabular}

$\mathrm{ARR}=$ adjusted relative risk; $95 \% \mathrm{CI}=95 \%$ confidence interval.

a Based on ACC veterans who served in Vietnam and who reported spraying herbicide $(n=662)$ versus those who reported no spraying of herbicide $(n=811)$. ARR obtained from Cox proportional hazards survival analysis modeling adjusting for rank, age at entry into follow-up, duration of military service, race, BMI, and smoking status. Data on herbicide spraying status, smoking, weight, and height were obtained from the ACC Vietnam Health Study (1). Mortality determined through December 31, 2005. Not all mortality categories are presented because of small numbers.

${ }^{b}$ Mainly mortality from malignant cancers, other major noncancer diseases, and external causes.

${ }^{\mathrm{c} M a r g i n a l l y ~ s i g n i f i c a n t}(p=.0506)$.

${ }^{\mathrm{d}}$ Mainly malignant neoplasms without specification of site.

(30). Although cause of death on the death certificate was not verified in this study, misclassification errors would be expected to be equally distributed across the cohorts and general population. Nevertheless, the NDI-Plus mechanism that was used in this research to obtain cause of death information has been shown to produce comparable results with approaches based on requests to state vital statistics offices with deaths coded by nosologists $(31,32)$.

The completeness of the various available mortality databases that were used in this study of Vietnam-era veterans has also received careful review (33). This study used information combined from the VA BIRLS Death File and the SSA Death Master File. It was found that VA death reporting of Vietnam-era veterans to be approximately $90 \%$ complete by the VA BIRLS files and $96 \%$ complete when used in conjunction with the SSA Death Master File. There was no substantial difference in ascertainment rate by Vietnam service status of deceased veterans (Vietnam veterans, 98\%; non-Vietnam veterans, 95\%) (33). The other national mortality data source which is considered the "gold standard" is the National Death Index (34). However, it can be expensive to use for a large cohort with a long follow-up period. In addition, the NDI does not include deaths before 1979. In our study, the start of vital status follow-up was 1973 or earlier.

This study was also limited by an inability to report that a statistically significant difference actually exists between the cohorts because of small sample sizes for many of these mortality categories. For example, considering mortality from respiratory system cancer among non-Vietnam veterans, we would need a sample approximately six times the size of the current sample ( $\beta=0.20$ with "two-sided" $[\alpha=0.05]$ sample size calculation) for an ARR $=1.29$ to represent the smallest detectable measure of association. In other words, an ARR of approximately 1.8-1.9 would need to be attained to detect a significant difference between the two cohorts given the size of the sample.

The lack of information on confounding factors, including smoking and alcohol use, dietary habits, and post-service occupational exposure, was a limitation. For example, inhalation of cigarette smoke is one of the most important risk factors for many nonmalignant respiratory diseases. The lack of smoking history for the entire cohorts of Vietnam and non-Vietnam veterans can be a major limitation in interpreting the study findings related to respiratory diseases. However, a subanalysis involving a comparison of approximately one half of the original ACC Vietnam veteran cohort who participated in a health survey in 1999/2000 still indicated that those who reporting handling/spraying herbicides were at a greater risk of death caused by respiratory cancer (ARR, 1.35; 95\% CI, $0.53-3.43$ ) and nonmalignant respiratory diseases (2.24; 0.42-11.83) even after adjusting for smoking status. Although the findings were not statistically significant as the result of small sample size, a similar pattern of elevated risk of respiratory diseases among Vietnam veterans with greater opportunity for herbicide exposure after controlling for smoking history lends support to the findings from the entire cohort of ACC Vietnam veterans.

A major strength of this study is the selection of a cohort of Vietnam veterans who had documented occupational exposure to herbicides in Vietnam and a comparison cohort of veterans who were in the same military occupation but who did not serve in Vietnam. A comparison to the U.S. male population alone may bias the results because of a "healthy veteran effect." Because of initial screening for military service, requirements to maintain certain physical standards, and better access to medical care during and after military service, a veteran cohort usually has a better survival rate than a comparable segment of the general population. This "healthy veteran effect" was demonstrated in the current study in that a vast majority of SMR values among non-Vietnam veterans were less than 1.0 indicating that even three decades after military service, there were still measurable effects from having been in the military. Therefore, a small increase in the risk of death from various causes in Vietnam veterans will not be detected, if one compares the mortality experience of Vietnam veterans only with the U.S. population. A follow-up period of more than three decades for the cohorts should be also considered a strength of the study because diseases with long latency periods, like many cancers, should already have begun to be manifested. 
In summary, Army Chemical Corps Vietnam veterans who were occupationally exposed to herbicides experienced a significant excess in mortality from diseases of the respiratory system (COPD) in comparison with their non-Vietnam veteran peers, and all causes, respiratory cancer, miscellaneous cancers, and nonmalignant respiratory disease as compared with U.S. males. Our findings are consistent with the results from several studies of workers who were occupationally exposed to herbicides and dioxin. In light of specific study limitations and the unique nature of military duties assigned to these veterans, the results from the study must be interpreted cautiously and may not be generalizable to Vietnam veterans as a whole.

The authors gratefully acknowledge the contributions of Ms. Nancy Dalager, MS (retired, Environmental Epidemiology Service, VA, Washington DC), who was a major contributor to the research produced on Vietnam-era Army Chemical Corps veterans.

\section{REFERENCES}

1. Kang HK, Dalager NA, Needham LL, Patterson DG, Lees PSJ, Yates K, et al. Health status of Army Chemical Corps Vietnam veterans who sprayed defoliant in Vietnam. Am J Ind Med. 2006;49:875-884.

2. Institute of Medicine of the National Academies. Veterans and Agent Orange. Update 2006. Washington, DC: The National Academies Press; 2007.

3. Institute of Medicine of the National Academies. Veterans and Agent Orange. Update 2008. Washington, DC: The National Academies Press; 2009.

4. Dalager NA, Kang HK. Mortality among Army Chemical Corps Vietnam veterans. Am J Ind Med. 1997;31:719-726.

5. International Classification of Diseases: Manual of the International Statistical Classification of Diseases, Injuries, and Causes of Death. 9th Revision, Vol. 1. Geneva: World Health Organization; 1977.

6. Thomas TL, Kang HK. Mortality and morbidity among Army Chemical Corps Vietnam veterans: A preliminary report. Am J Ind Med. 1990;18:665-673.

7. Allison PD. Competing risks. In: Survival Analysis Using the SAS System ${ }^{\circledR}$. A Practical Guide. Cary, NC: SAS Institute; 1995:185-209.

8. Rothman KJ. No adjustments are needed for multiple comparisons. Epidemiology. 1990;1:43-46.

9. Perneger TV. What's wrong with Bonferroni adjustments. BMJ. 1998;316:1236-1238.

10. Kogevinas M, Becher H, Benn T, Bertazzi PA, Boffetta P, Bueno-de-Mesquita $\mathrm{HB}$, et al. Cancer mortality in workers exposed to phenoxy herbicides, chlorophenols, and dioxins. An expanded and updated international cohort study. Am J Epidemiol. 1997;145:1061-1075.

11. Ott MG, Zober A. Cause specific mortality and cancer incidence among employees exposed to 2,3,7,8-TCDD after a 1953 reactor accident. Occup Environ Med. 1996;53:606-612.

12. Fingerhut MA, Halperin WE, Marlow DA, Piacitelli LA, Honchar PA, Sweeney MH, et al. Cancer mortality in workers exposed to 2,3,7,8-tetrachlorodibenzo-p-dioxin. N Eng J Med. 1991;324:212-218.

13. Coggon D, Pannett B, Winter PD, Acheson ED, Bonsall J. Mortality of workers exposed to 2-methyl-4 chlorophenoxyacetic acid. Scand J Work Environ Health. 1986;12:448-454.

14. ADVA (Australian Department of Veterans Affairs). Australian National Service Vietnam Veterans: Mortality and Cancer Incidence. Canberra: Department of Veterans' Affairs; 2005.
15. ADVA. The Third Australian Vietnam Veterans Mortality Study 2005. Canberra: Department of Veterans' Affairs; 2005.

16. CDVA (Commonwealth Department of Veterans' Affairs). Mortality of Vietnam Veterans: The Veteran Cohort Study. A Report of the 1996 Retrospective Cohort Study of Australian Vietnam Veterans. Canberra: Department of Veterans' Affairs; 1997.

17. Michalek JE, Ketchum NS, Akhtar FZ. Postservice mortality of US Air Force veterans occupationally exposed to herbicides in Vietnam: 15-Year follow-up. Am J Epidemiol. 1998;148:786-792.

18. Pavuk M, Michalek JE, Schecter A, Ketchum NS, Akhtar FZ, Fox KA. Did TCDD exposure or service in Southeast Asia increase the risk of cancer in Air Force Vietnam veterans who did not spray Agent Orange? J Occup Environ Med. 2005;47:335-342.

19. Pesatori AC, Zocchetti C, Guercilena S, Consonni D, Turrini D, Bertazzi PA. Dioxin exposure and non-malignant health effects: A mortality study. Occup Environ Med. 1998;55:126-131.

20. O’Toole BI, Marshall RP, Grayson DA, Schureck RJ, Dobson M, Ffrench M et al. The Australian Vietnam Veterans Health Study: II. Self-reported health of veterans compared with the Australian population. Int J Epidemiol. 1996;25:319-330.

21. Sweeney MH, Calvert GM, Egeland GA, Fingerhut MA, Halperin WE, Piacitelli LA. Review and update of the results of the NIOSH medical study of workers exposed to chemicals contaminated with 2,3,7,8-tetrachlorodibenzodioxin. Teratog Carcinog Mutagen. 1997-1998;17:241-247.

22. Steenland K, Piacitelli L, Deddens J, Fingerhut M, Chang LI. Cancer, heart disease, and diabetes in workers exposed to 2,3,7,8-tetrachlorodibenzo-p-dioxin. J Natl Cancer Inst. 1999;91:779-786.

23. Dalager NA, Kang HK, Burt VL, Weatherbee L. Non-Hodgkin's lymphoma among Vietnam veterans. J Occup Med. 1991;33:774-779.

24. The Selected Cancers Cooperative Study Group. The association of selected cancers with service in the US military in Vietnam, I. Non-Hodgkin's lymphoma. Arch Intern Med. 1990;150:2473-2483.

25. Dalager NA, Kang HK, Burt VL, Weatherbee L. Hodgkin's disease and Vietnam service. Ann Epidemiol. 1995;5:400-406.

26. The Selected Cancers Cooperative Study Group. The association of selected cancers with service in the US military in Vietnam, III. Hodgkin's disease, nasal cancer, nasopharyngeal cancer, and primary liver cancer. Arch Intern Med. 1990;150:2495-2505.

27. Engel LW, Strauchen JA, Chiazze L, Heid M. Accuracy of death certification in an autopsied population with specific attention to malignant neoplasms and vascular diseases. Am J Epidemiol. 1980;111:99-112.

28. Percy C, Stanek E, Gloeckler L. Accuracy of cancer death certificates and its effect on cancer mortality statistics. Am J Public Health. 1981;71:242-250.

29. Smith Sehdev AE, Hutchins GM. Problems with proper completion and accuracy of the cause-of-death statement. Arch Intern Med. 2001;161:277-284.

30. Sirken MG, Rosenberg HM, Chevarley FM, Curtin LR. The quality of cause-of-death statistics. Am J Public Health. 1987;77:137-139.

31. Doody MM, Hayes HM, Bilgrad R. Comparability of National Death Index Plus and standard procedures for determining causes of death in epidemiologic studies. Ann Epidemiol. 2001;11:46-50.

32. Sathiakumar N, Delzell E, Abdalla O. Using the National Death Index to obtain underlying cause of death codes. J Occup Environ Med. 1998;40:808-813.

33. Page WF, Mahan CM, Kang HK. Vital status ascertainment through the files of the Department of Veterans Affairs and the Social Security Administration. Ann Epidemiol. 1996;6:102-109.

34. Fisher SG, Weber L, Goldberg J, Davis F. Mortality ascertainment in the veteran population: alternatives to the National Death Index. Am J Epidemiol. 1995;141:242-250. 